\title{
A integração de tecnologias digitais na formação profissional docente: uma nova profissionalidade docente
}

\author{
Vânia Graça ${ }^{a}$, Paula Quadros-Flores ${ }^{b}$, Altina Ramos ${ }^{c}$ \\ ${ }^{a}$ Centro de Investigação e Inovação em Educação (inED), Escola Superior de Educação, Politécnico \\ do Porto, Portugal, vaniaadias14@gmail.com, ${ }^{\text {b }}$ Centro de Investigação e Inovação em Educação \\ (inED), Escola Superior de Educação, Politécnico do Porto, Portugal, paulaqflores@ese.ipp.pt, \\ ${ }^{\mathrm{c} C e n t r o ~ d e ~ I n v e s t i g a c ̧ a ̃ o ~ e m ~ E d u c a c ̧ a ̃ o ~(C I E d), ~ I n s t i t u t o ~ d e ~ E d u c a c ̧ a ̃ o, ~ U n i v e r s i d a d e ~ d o ~ M i n h o, ~}$ \\ Portugal, altina@ie.uminho.pt
}

\begin{abstract}
Resumo
A formação inicial docente assume uma responsabilidade impar na formação de futuros educadores e professores que devem sair dotados de saberes e competências científicas, técnicas, deontológicas e pedagógicas adequadas ao uso de tecnologias digitais de forma consciente, critica e criativa. $O$ presente estudo tem como objetivo conhecer o pensamento de futuros docentes relativamente aos seus saberes e atitudes face à integração curricular das Tecnologias de Informação e Comunicação (TIC). Este trabalho desenvolve-se no âmbito do Projeto IFITIC que tem como objetivo repensar a prática educativa com TIC na formação inicial de futuros docentes de modo a promover a inovação metodológica na Educação Préescolar e no $1 .^{\circ}$ e 2. ${ }^{\circ}$ Ciclos do Ensino Básico. Recorreu-se a uma pesquisa/metodologia survey. Para a recolha de dados aplicouse um inquérito por questionário, com questões fechadas, a estudantes da Educação Básica e Mestrado Profissionalizante de duas instituições de Ensino Superior público do Norte de Portugal. Neste estudo serão analisadas três questões desse questionário. Os resultados revelam que a) há uma fragilidade na formação em TIC; b) têm mais conhecimentos de ferramentas de recolha de informação e de apresentação do que de ferramentas que favorecem a compreensão, a construção de conhecimentos, a avaliação, a comunicação e a publicação e partilha; c) a maioria assume uma atitude positiva quanto ao uso educativo das TIC e sente-se apoiada pela Instituição de Ensino Superior.
\end{abstract}

Palavras-chave: Formação inicial docente, nova profissionalidade docente, Tecnologias de Informação e Comunicação (TIC). 


\section{Introdução}

A integração das Tecnologias da Informação e da Comunicação tem aberto novas possibilidades na educação promotoras de uma nova profissionalidade docente (Nóvoa, 2013). Neste sentido, é importante promover tempos de experiência e de aprendizagens relativos à integração das TIC nas práticas educativas (Estudos da Office of Technology Assessment, 1995) e desenvolver competências digitais específicas para a profissão, por forma a que os docentes sejam capazes de aproveitar o potencial das tecnologias digitais para melhorar e inovar a educação (Lucas \& Moreira, 2018), e para responder ao perfil do aluno à saída da escolaridade obrigatória (Oliveira-Martins, 2017). Através da observação de práticas educativas de professores, estudos concluem que a introdução das tecnologias deve ser encarada como um processo gradual, pelo qual os professores têm de passar, sendo que Costa (2008) identifica a primeira etapa como a Entrada onde se aprende o essencial, seguida da Adoção e Adaptação no suporte de ensino tradicional, a Apropriação adequando a projetos interdisciplinares e colaborativos e a invenção. Também Quadros-Flores (2016) revela existirem quatro etapas na correlação entre recursos, metodologias na realização de práticas educativas: a etapa da Descoberta em que os professores valorizam o computador, a impressora e o gravador/leitor $\mathrm{CD}$, sendo que a probabilidade de utilização desses recursos aumenta com a sua disponibilidade; na etapa da Experimentação, os professores já valorizam aplicações, softwares e outras ferramentas digitais sendo que a probalidade de utilização varia com a disponibilidade desses recursos na escola (nestas primeiras etapas ajustam a utilização dos recursos ao paradigma tradicional); a etapa da Mudança ocorre nos professores que dispõem de Rede Wireless, Quadro Interativo e Câmaras de vídeo, atualmente integradas no Smartphone; na etapa da Seleção demostram maturidade na seleção de recursos e na realização de práticas inovadoras, democráticas, transferíveis, atuais, úteis, que respondem a problemas atuais alterando o perfil de professor e de aluno: deixaram de ser consumidores de informação para também serem produtores da mesma orientando e facilitando ambientes de aprendizagem integrados numa aprendizagem ubíqua. A última etapa é a mais desejada na formação inicial de professores preparando futuros professores num paradigma construtivista e de utilização didática da tecnologia (Litwin, 2009). Por isso, interessa-nos conhecer a realidade do professor estagiário para melhorar a formação inicial docente, tendo um olhar atento sobre estes 5 estádios de desenvolvimento na utilização pedagógica das tecnologias ao longo da análise. Ainda neste sentido, de referir o estudo de Raposo-Rivas et al (2020), cujo inquérito aplicado foi o mesmo deste estudo, que mostra que os saberes e formação dos estudantes sobre TIC são modestos, pois apenas revelam ter adquido alguns conhecimentos. Todavia, valorizam e classificam a formação recebida de boa (41\%), mas são mais o que usam a Internet, o correio eletrónico, o processador de texto, apresentação de diapositivos que os que usam a câmara fotográfica, o 
quadro interativo, softwe educativo e folha de cálculo. Neste sentido, nas práticas educativas os alunos investigam $(86,2 \%)$, utilizam jogos $(65,5 \%)$, compreendem textos $(58,6 \%)$ e realizam apeesentações multimédia $(55,2 \%)$.

\subsection{Metodologia}

Recorreu-se a uma pesquisa/metodologia survey, também conhecida por levantamento (Gil, 2002). É um tipo de metodologia quantitativa que é utilizada para avaliar os pensamentos, opiniões e sentimentos de grupos de indivíduos. Assim, procede-se à solicitação de informações a um grupo significativo de pessoas acerca do problema a estudar (Gil, 2002). A recolha de dados foi feita através de um inquérito por questionário com perguntas fechadas a 111 estudantes em formação inicial de professores. Neste artigo tratamos alguns dos dados quantitativos. As características da amostra e o momento em que ocorre a investigação têm influência no valor da informação recolhida. Assim, salienta-se que o inquérito foi aplicado no final do ano letivo, sendo o universo do estudo estudantes da Licenciatura de Educação Básica (76\%), destes 60\% frequentava a Unidade Curricular de Iniciação à Prática Profissional III: Observação e Cooperação nos Contextos Educativos (IPPIII) que inclui um momento de Estágio, e de um Mestrado profissionalizante (24\%) que inclui a Prática Pedagógica Supervisionada. A maioria (63\%) tinha idades compreendidas entre 19-21 anos, é do género feminino (97\%) e encontrava-se a estudar em instituições de ensino do tipo Politécnico (86,5\%). Este resultado traduz uma amostra significativa e a boa aceitação do inquérito junto dos estudantes.

\subsection{Análise e discussão de resultados}

\subsubsection{A formação ministrada nas instituições de formação de professores}

Considerou-se extremamente importante compreender como os estudantes em formação inicial de professores avaliam a sua formação TIC recebida por parte das suas instituições de formação (figura 1).

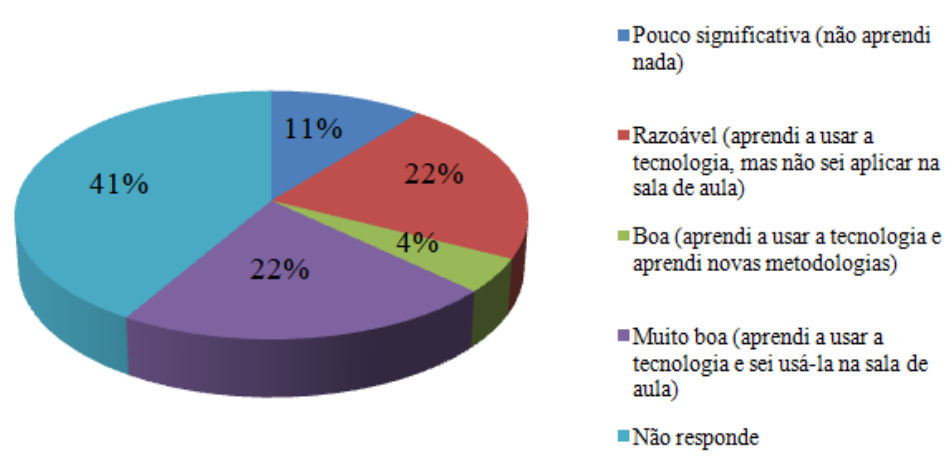

Fig. 1 Avaliação da formação TIC pelos futuros docentes. 
Segundo a figura 1 , uma percentagem significativa de estudantes $(41 \%)$ não respondeu à questão, o que é revelador de alguma preocupação, sobretudo porque $11 \%$ dos futuros professores refere que a formação TIC ministrada pela instituição de formação de professores foi "Pouco significativa". Não existem dados nas respostas dos inquiridos que nos possibilitam avançar com uma explicação, mas consideramos a hipótese de haver factores externos que possam contribuir para este resultado, entre eles, por exemplo, a posição da Unidade Curricular "Tecnologias da Informação e Comunicação Multimédia" no Plano de estudos (1. ${ }^{\circ}$ ano), pois é muito importante o sentido e o significado que os alunos atribuem à utilização das TIC. Este aspeto poderá ser alvo de investigação futura.

Um olhar global mostra que $48 \%$ tem uma opinião positiva, sendo que $22 \%$ classificaram a sua formação em TIC como "Muito boa", pois aprenderam a usar tecnologia e sabem usar na sala de aula", mas também de "Razoável", afirmando que possuem conhecimentos de recursos digitais, embora ainda não os tenham mobilizado em sala de aula (realçamos que a amostra inclui uma percentagem significativa de estudantes a frequentar a licenciatura em Educação Básica e que, por isso, ainda não aplicam nos contextos educativos reais). Assim, o resultado mostra, por um lado, que a própria formação inicial docente preocupa-se em integrar na formação dos estudantes metodologias e tecnologias digitais, por outro lado alerta para uma reflexão que encontre soluções que poderão contribuir para melhor preparar os estudantes para desafios futuros inerentes à profissionalidade docente, aliás como já reforçam alguns autores (Carneiro, 2014; Costa, 2009; Papert, 1994; Jonassen, 1996, 2000).

\subsubsection{Conhecimentos dos estudantes em formação inicial de professores}

Foi objetivo compreender que conhecimentos técnicos os estudantes em formação inicial possuíam, nomeadamente em determinadas áreas. As respostas encontram-se refletidas na figura 2 .

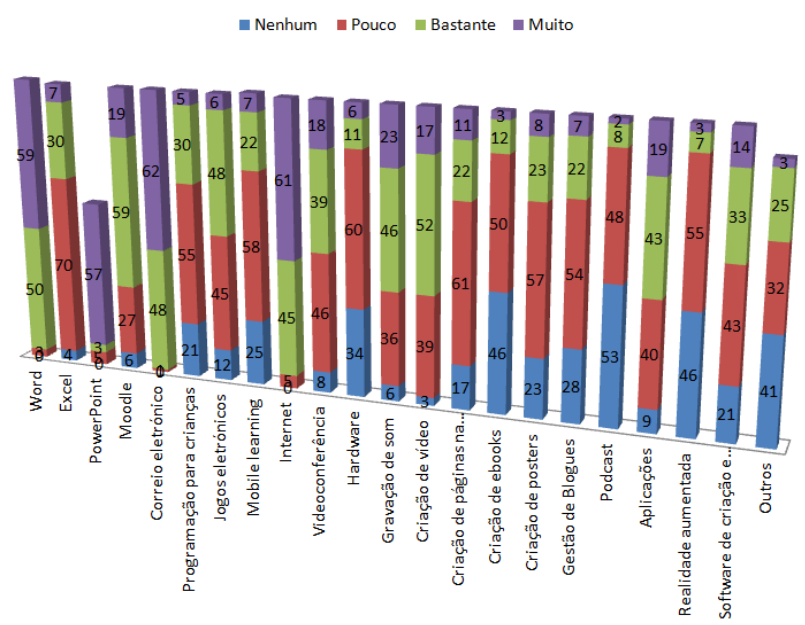

Fig.2 Conhecimentos técnicos dos futuros docentes. 
Ao avaliarem os seus conhecimentos técnicos, a maioria dos futuros docentes consideram ter "Muitos" conhecimentos em Correio eletrónico (62\%), Internet (61\%), Word (59\%) e PowerPoint (57\%), ferramentas digitais que potenciam a investigação, a consolidação e exposição, uma etapa elementar na escala de desenvolvimento. Constata-se ainda, que os futuros professores possuem "Bastantes" conhecimentos em Moodle (59\%), Criação de vídeo (52\%), Word (50\%), Correio eletrónico (48\%), Jogos eletrónicos (48\%), Gravação de som (46\%) e Internet (45\%). Relativamente aos "Poucos" conhecimentos que os estudantes possuem são relativos ao Excel (70\%), Criação de páginas na internet (61\%), Mobile Learning (58\%), Criação de posters (57\%), Realidade Aumentada e Programação para crianças (55\%). As respostas "Nenhuns" conhecimentos referem-se a Podcast (53\%), Criação de ebooks e Realidade Aumentada (46\%). Este resultado revela que os estudantes possuem conhecimentos técnicos modestos em ferramentas digitais, nomeadamente de comunicação. No entanto, os conhecimentos manisfestados permitem realizar práticas diversificadas, o que significa que apesar de se verificarem fragilidades nos saberes em TIC, existem algumas potencialidades de saber-fazer diferente da esfera tradicional, dependendo sobretudo da capacidade de cada um construir um conhecimento integrado que combina os saberes técnicos, pedagógicos e científicos do currículo. Para Nóvoa (2009), a formação docente para a literacia digital é relevante para a construção de processos de inclusão que respondam aos desafios da diversidade e no desenvolvimento de métodos apropriados de utilização de tecnologias digitais mais atualizadas, pelo que pode ser a chave de ignição para a promoção de mudanças na escola (Alves, 2020).

\subsubsection{Atitude dos estudantes em formação inicial de professores face à integração} pedagógica das TIC

Foi também objetivo desta análise compreender que avaliação os futuros professores atribuíam aos seus conhecimentos quanto à utilização pedagógica das TIC (figura 3).

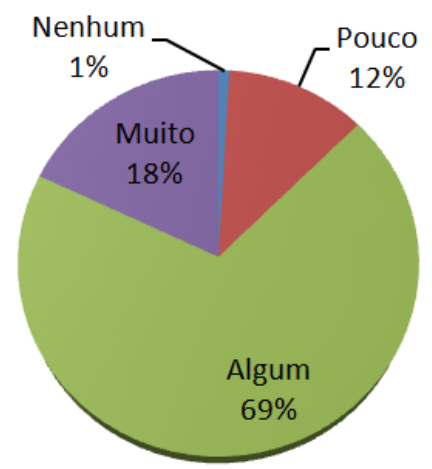

Fig. 3 Conhecimentos de utilização pedagógica das TIC dos futuros docentes.

Ao avaliarem os seus conhecimentos quanto à utilização pedagógica das TIC, a maioria dos inquiridos considera ter "Algum" (69\%) conhecimento na integração pedagógica das TIC o 
que revela, por um lado, um impacto positivo do esforço realizado por algumas Unidades Curriculares, mas por outro lado realça a necessidade de melhorias para que estes compreendam as inúmeras potencialidades e estratégias sobre a utilização pedagógica das TIC em sala de aula (Almeida \& Valente, 2011). Este resultado tem sentido, pois apenas $24 \%$ dos nossos estudantes são alunos de mestrado, sendo que compreende-se que $18 \%$ referem ter "Muito" conhecimento sobre a mobilização pedagógica das TIC na sala de aula. Note-se que os estudantes da amostra referem ter "Poucos" conhecimentos na utilização didática das TIC (12\%), este resultado talvez corresponda aos estudantes da Educação Básica que ainda não tiveram oportunidade de aprender a integrar recursos digitais nas práticas educativas. De um modo geral, percebe-se que é necessário reforçar competências digitais e saberes pedagógicos de utilização das TIC, no âmbito da formação inicial docente, e estes vão redimensionar a profissionalidade docente com novos traços que arquitetam a escola numa nova era (Quadros-Flores \& Raposo-Rivas, 2017).

Foi importante compreender que tipo de atividades os futuros docentes realizavam com os seus alunos (figura 4 ).

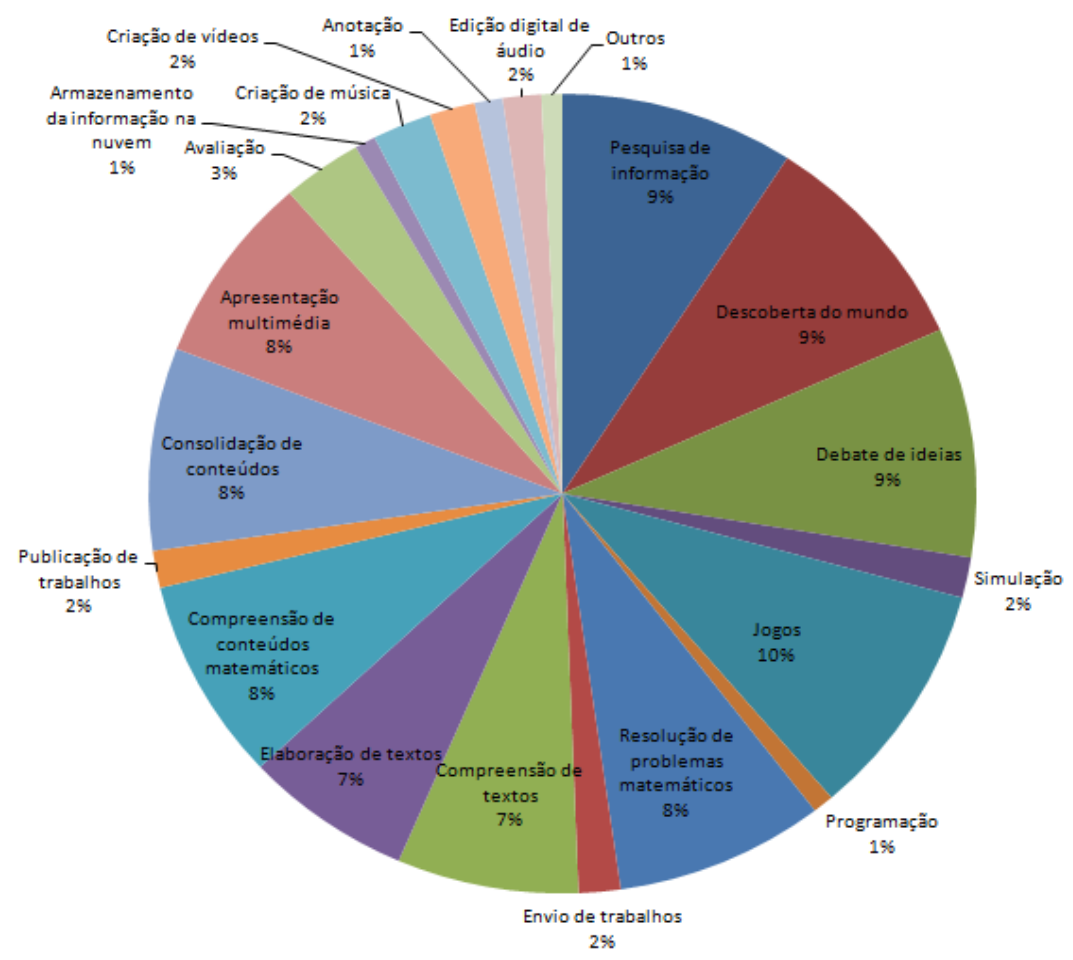

Fig. 4 Atividades realizadas pelos futuros docentes

Verifica-se a preocupação por parte dos futuros professores em promover atividades diversificadas e com intencionalidade educativa: Jogos (10\%); Debate de ideias (9\%); 
Descoberta do mundo (9\%); Pesquisa de informação (9\%); Apresentação multimédia (8\%); Compreensão de contéudos matemáticos (8\%); Consolidação de conteúdos (8\%). Este panorama não evidencia numa tendência em especial, mas revela uma harmonia entre os ssaberes técnicos e pedagógicos manisfestados. Assim, de um modo geral, constata-se no gráfico que os estudantes inquiridos privilegiam um ambiente lúdico e atividades centradas na pesquisa, descoberta, debate de ideias, apresentação, resolução de problemas, compreensão de conteúdos, consolidação de saberes, elaboração. Para uns poderá, eventualmente, representar um momento de adoção/adaptação ao paradigma tradicional, para outros um momento de descoberta/experimentação e ainda para outros uma tentativa de mudança, integrando não só novas ferramentas como também novos modos de ensinar a aprender num perfil como define Oliveira-Martins (2017). Veja-se, atividades como Programação (1\%), Criação de vídeo (2\%), Simulação (2\%), Edição digital de áudio (1\%), utilização da "Nuvem" (1\%) são pouco expressivas nas práticas educativas, o que revela uma lacuna a melhorar. O ritmo acelerado de inovações tecnológicas digitais e as suas potencialidades pedagógicas no processo de ensino e aprendizagem exigem uma permanente atualização do papel do professor (Silva, 2014) e, por conseguinte, um novo olhar sobre a profissão docente.

\section{Agradecimentos}

Este trabalho é financiado por fundos nacionais através da FCT - Fundação para a Ciência e a Tecnologia, I.P., no âmbito do projeto UIDB/05198/2020 (Centro de Investigação e Inovação em Educação, inED).

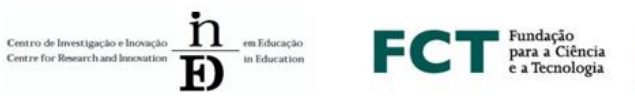

REPÚBLICA PORTUGUESA

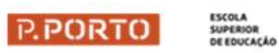

\section{Referências}

Almeida, M. \& Valente, J. (2011). Tecnologias e currículo: trajetórias convergente ou divergentes?. São Paulo: Paulus.

Alves, E. (2020). Porque não consigo Ensinar com Tecnologias nas Minhas Aulas?. Porto Alegre: Editora Fi.

Carneiro, J. A. (2014). Web 2.0 e trabalho colaborativo como estratégia de formação de professores. Dissertação de Mestrado em Educação na área de especialização em Educação e Tecnologias Digitais doi: http://hdl.handle.net/10451/16038

Costa, F. A. (2009). Um breve olhar sobre a relação entre as tecnologías digitais e o currículo no início do Séc. XXI. Actas da VI Conferência Internacional de Tecnologias de Informação e 
A integração de tecnologias digitais na formação profissional docente: uma nova profissionalidade docente

Comunicação na Educação (pp. 293-307). Braga: Centro de Competência da Universidade do Minho.

Costa, F. (2008). Competências TIC. Estudo de Implementação, V.1. Lisboa: Gabinete de Estatística e Planeamento da Educação (GEPE).

Gil, C. (2002). Como elaborar projetos de pesquisa (2.a . ed.) São Paulo:Atlas.

Jonassen, D. (2000). Computers as mindtools for schools: engaging critical thinking. Upper Saddle River, N.J.: Pearson Education.

Jonassen, D. (1996). Computers in the classroom: mindtools for critical thinking. Englewood Cliffs, N.J.: Merrill.

Litwin, E. (2009). La tecnología educativa en el debate didáctico contemporáneo. In. E. Litwin. (Ed.). Tecnologías educativas en tiempos de internet. Buenos Aires: Amorrortu Editores.

Lucas, M. \& Moreira, A. (2018). Quadro Europeu de Competência Digital para Educadores. Aveiro: UA Editora - Universidade de Aveiro. ISBN: 978-972-789-580-9.

Nóvoa, A. (2013). Entrevista com o prof. Antonio Nóvoa. Olhares: Revista Do Departamento De Educação Da Unifesp, 1(1), 416-418. doi: https://doi.org/10.34024/olhares.2013.v1.141

Nóvoa, A. (2009). Professores imagens do futuro no presente. Lisboa: Educa.

Office of Technology Assessment (1995). Teachers and technology: Making the connection (No. OTA-EHR-616): Office of Technology Assessment, US Congress.

Oliveira-Martins, G. (Coord.). (2017). Perfil dos Alunos à Saída da Escolaridade Obrigatória. Lisboa: Ministério da Educação/DGE.

Papert, S. (1994). A máquina das crianças: repensando a escola na era da informática. Porto Alegre, Brasil: Artes Médicas.

Quadros-Flores, P. \& Raposo-Rivas, M. (2017). A inclusão de tecnologias digitais na educação: (re)construção da identidade profissional docente na prática. Revista Prácticum, 2(2) 2-17. ISSN 2530-4550.

Quadros-Flores, P. (2016). A Identidade Profissional Docente e as TIC: Estudos de Boas Práticas no $1^{\circ}$ Ciclo do Ensino Básico na região do Porto. Berlin: Novas Edições Acadêmicas.

Raposo-Rivas, M., Quadros-Flores, P., Martínez-Figueira, E., Silva, A., \& Tellado-González, F. (2020). Utilización de TIC para la innovación en el Prácticum. Revista Prácticum 5(1) 22-36. DOI: https://doi.org/10.24310/RevPracticumrep.v5i1.9814.

Silva, B. A. (2014). Aplicação e uso de tecnologias digitais pelos professores do ensino superior no Brasil e Portugal. Revista Educação, Formação \& Tecnologias, 7(1), 3-18. 